\title{
EVALUATING DIFFERENT MODELS USED FOR PREDICTING THE INDOOR MICROCLIMATIC PARAMETERS OF A GREENHOUSE
}

\author{
ElANCHEZHIAN, A. - BASAK, J. K. - PARK, J. - KHAN, F. - OKYERE, F. G. - LEE, Y. - \\ BhuJel, A. - LEe, D. - Sihalath, T. - KiM, H. T. \\ Department of Bio-systems Engineering, Gyeongsang National University, Institute of \\ Agriculture \& Life Science, Jinju 52828, South Korea \\ *Corresponding author \\ e-mail: bioani@gnu.ac.kr; phone: +82-55-772-1896; fax +82-55-772-1899
}

(Received $9^{\text {th }}$ Sep 2019; accepted $25^{\text {th }}$ Nov 2019)

\begin{abstract}
A robust adaptive model to predict and to control the greenhouse microclimatic condition is pivotal for better crop production and growth. The current research assesses the use of multiple linear regression (MLR), autoregressive integrated moving average (ARIMA), and multi-layered perceptron (MLR) for predicting indoor microclimate greenhouse, located in South Korea. The data were collected from the local weather station and regional weather station data named M1 (local weather station data combined with the regional weather station data), M2 (regional weather station data), and M3 (local weather station data), which were used as the input variables for the prediction. Four dependent variables were predicted (two temperature variables and two humidity variables) by each of the models using M1, M2, and M3 data sets. Performances of the models were evaluated with the coefficient of determination $\left(R^{2}\right)$, the root mean square error (RMSE), the mean square error (MSE), and the mean absolute error (MAE). The simulation results showed that the prediction by the MLP model was highly correlated to the measured data with less RMSE, MSE, and MAE. Besides, seasonal based analysis results reinforce that the MLP performs a better simulation in different environmental conditions. Moreover, the M1 data were propitious for better performance than other data sets, which specifically improves the accuracy of the simulation results for humidity predictions. The present study developed a simple and powerful MLP model to predict the microclimate of the greenhouse, which may integrate into greenhouse controller devices through cloud technology in the future.
\end{abstract}

Keywords: ARIMA, greenhouse, indoor microclimate, MLP, MLR, model comparison

\section{Introduction}

Currently, one of the major challenges in worldwide agricultural productivity is climate change. Reducing food hunger is becoming an immense challenge due to the abnormal increase in the world population. Adopting precision farming methodologies such as greenhouse farming technology protect from the vulnerability of agriculture production (Kurt et al., 2017). From the last few decades, precision farming methodologies have boosted agriculture production due to the emergence in advanced technologies such as sensors, actuators and microprocessors, IoT based greenhouse systems, and big data analytics. In recent years, production in greenhouses has become more popular than ever before. The global smart greenhouse market is estimated to grow from 680.3 million in 2016 to 1.31 billion USD by 2022 (Leonetti, 2018). The key factors driving the smart greenhouse market include; improving the indoor farming space, vegetation on farmer preferences, high demand for quality, favorable government regulations, etc. The indoor microclimatic parameters such as temperature and humidity is an essential aspect of controlling the crop interaction with the environment. Enhancing microclimatic conditions in a greenhouse leads to improve crop quality and quantity of 
production since these crop properties directly influenced by the microclimate parameters (Santosh et al., 2017). Therefore, considering control of temperature and humidity is essential when a farmer plans to start planting in greenhouse facilities.

A robust, adaptive, and accurate model is essential to predict the indoor temperature and humidity of the greenhouse to develop an ideal control strategy for a greenhouse microclimate (Luan et al., 2011). Various static and dynamic models have been developed to predict and control microclimatic conditions in earlier studies (Lu and Viljanen, 2009; He and Ma, 2010; He et al., 2014; Shi et al., 2018). Most often, substantial studies carried out regression models, time series models, computer intelligence approaches, and hybrid approaches to predict the short term as well as long-term time series based variables (Cheng and Ni-Bin, 2011). A comprehensive performance assessment of the different prediction models helps to develop an ideal control strategy for greenhouse microclimate (Uchida and Pieters, 2004). The current study is hypothesised to make a comparative study between the performance of the physical models and the computational models. Likewise, the foremost objective of this study is to evaluate the performance of the physical model (multiple linear regression (MLR)), the time series forecast model (autoregressive integrated moving average (ARIMA)) and the computational model (multi-layered perceptron (MLR) with back propagation-BB training algorithm) with limited input variables. Numerous studies considered the outdoor environmental parameters along with indoor parameters such as soil temperature, plant phenotypes, and ventilation as accessible input variables for predicting the indoor microclimate of a greenhouse (Lu and Viljanen, 2009; He and Ma, 2010). However, the present study performs the prediction of greenhouse microclimate using a minimum number of input variables. For the data collection, most of the researches established a specific local weather station rather than the regional weather station to model the indoor climate of a greenhouse (Behrang et al., 2010; Singh and Tiwari, 2017), besides various studies consider the regional weather stations data for their greenhouse indoor climate modeling (Liu et al., 2018; Shi et al., 2018). The other objective of the current study is to predict microclimate using local weather station (near to the greenhouse) environmental parameters as well as the regional weather station data from the zonal weather station.

\section{Literature review}

Regression models are more often developed and applied for prediction in fields such as greenhouse microclimate, energy consumption, heat transfer, meteorological forecast, business forecast, and others (Feinberg and Genethliou, 2005). Generally, MLR model performances include the incorporation of deterministic influences, stochastic influences, and exogenous influences. Researchers considered standard errors as the dominant central point for evaluating regression models. Taki et al. (2016) utilized an MLR model to predict the temperature, humidity, soil temperature, and soil moisture level of a greenhouse in Iran. That study proves that the regression model is capable of making accurate predictions with minimal root mean square error (RMSE) and a higher coefficient of determination $\left(\mathrm{R}^{2}\right)$. Likewise, several studies that employed MLR techniques for their predictions (Davis, 2003; Zhao and Xue, 2010).

Most climatic-based variables follow a series type of wave correlated to time so that the time series forecast models could contribute to series based predictions. Moving average, exponential smoothing, and autoregressive integrated moving average (ARIMA) are frequently used techniques in prediction, which performed by past observations; ARIMA is more prevalent among time-series predictions (Khashei and Bijari, 2011). 
Hasni et al. (2010) designed an ARIMA model to predict the temperature flow of a greenhouse. In that study, various time series models were utilized and stimulated to predict the greenhouse temperature from 11 days of data. That literature concluded that the ARIMA models could efficiently produce a better forecast for long seasonal time series with high frequency. However, these models could not provide an exact forecast, which could be considered as a supplemental tool for environmental planning and decision-making for a seasonal based prediction.

In recent years, the development of advanced software technologies creates a platform to govern and analyze big data using a computational approach, which includes; artificial neural networks (ANN), convolutional neural networks $(\mathrm{CNN})$, etc. ANN model is a robust computational method for classifying flow data, which may perform well for solving non-linear problems using their inner-parallel architecture (Atia and El-madany, 2017). Capabilities such as self-adaptive strategy, data-driven, extract the relationship between the inputs and outputs of a process, etc. makes ANN-based modeling as valuable and attractive for non-linear data predictions (Neshat et al., 2011). ANN models used with several algorithms including; multilayer perceptron (MLP), Support Vector Machine (SVM), backpropagation (BP), etc. which are included with or without various transfer functions. The performance of the models differs according to the description of the problem, target data, and processing time. MLP algorithm is popular among ANN models to solve various aspects of microclimatic prediction problems (Dombayci and Gölcü, 2009; Taki et al., 2015; Leopold et al., 2016). Since the MLR models have the capability to self-learn during the training, most of the studies are successful and statistically significant in terms of various error checking methods such as RMSE, Mean absolute error (MAE), and mean squared error (MSE).

Though there were performance tests between regression and ANN models in several researchers, most of the comparative studies have been carried out between the physical models and ANN models or else time series models and ANN (Taki et al., 2015, 2016; Hande et al., 2016; Nury et al., 2017). For instance, Taki et al. (2016) study made a comparison between the dynamic model and MLP model to predict the air temperature and roof temperature of a greenhouse and his literature concluded that the performance of MLP (ANN) model was better than the other models based on the small RMSE and mean absolute percentage error (MAPE). Mehdi et al. (2013) carried out a study about the accuracy of the prediction model between ANN, adaptive neuro-fuzzy inference system (ANFIS), and regression model and concluded that the MLR models are better in terms of simple and straightforward statistical methods then ANN. The efficiency of any model improved by the addition of more relevant input variables along with normalization. The current study used limited input details with non-preprocessed data.

\section{Materials and Methods}

\section{Experimental site, materials and data collection}

The study was conducted in a greenhouse facility, which maintained by the smart farm research center of Gyeongsang National University, South Korea, with GPS coordinates N35 $09^{\prime} 09^{\prime \prime}$, E128 $05^{\prime} 44.99^{\prime \prime}$ (Google earth). A flat arch-shaped, 2-layer polyethylene covering with $0.1 \mathrm{~mm}$ and $0.075 \mathrm{~mm}$ thickness patched, UV-Resistant greenhouse was used for this research. The dimensions of the greenhouse are shown in Figure 1 with more details. The greenhouse was entirely operated by a UBN Farmlink ${ }^{\mathrm{TM}}$ v 3.0 (South Korea) farm management technology that collects and stores the data from the sensor node. A 
wireless sensor node, which shown in Figure 2 was utilized to record the temperature and humidity data. In this research, two sets of temperature, humidity sensors were placed in the front and backside of the greenhouse which is displayed in Figure 1. The control system of the experimental site has three major parts that are the network controller, actuator, and wireless sensor nodes. All the electronic devices and data loggers were calibrated to minimize the device errors before the starting time of the experiment.

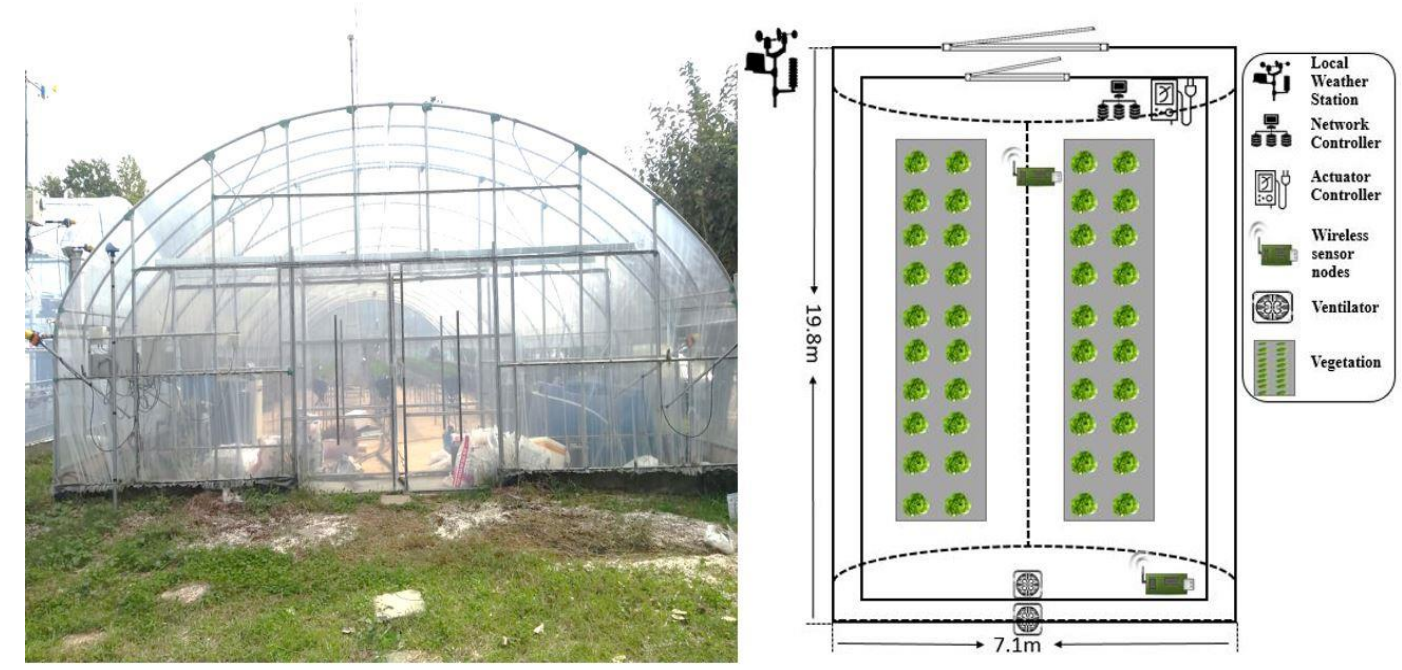

Figure 1. Image of the experimental greenhouse and layout of the experimental setup

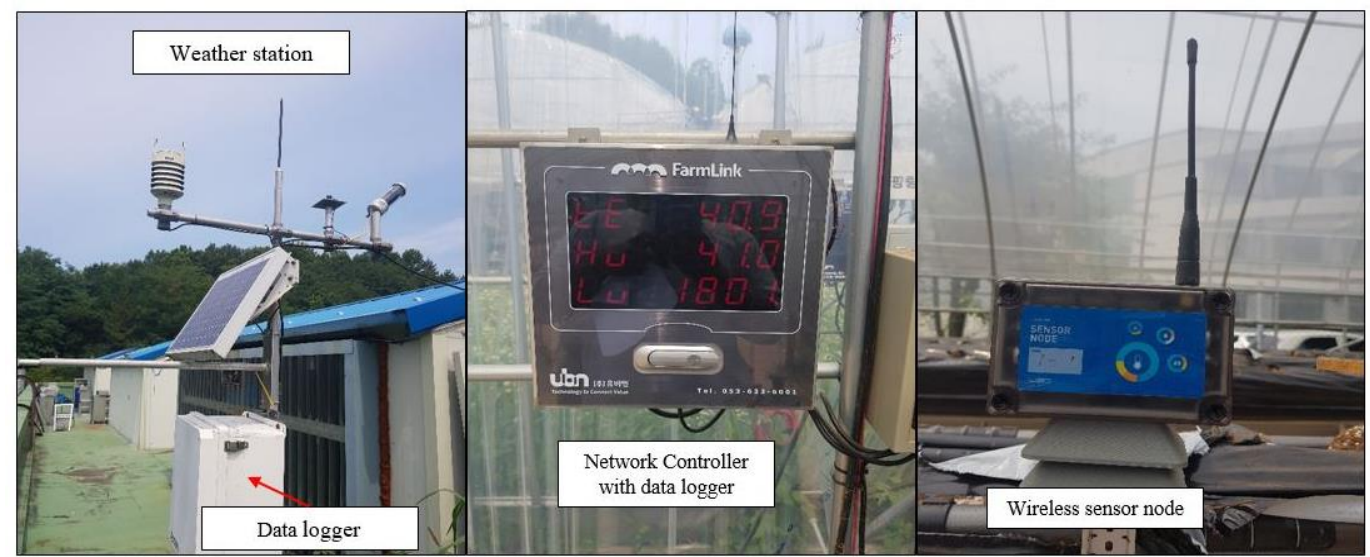

Figure 2. Images of local weather station, network controller with the data logger, wireless sensor nodes used in the experimental site

A weather station which is contiguous to the greenhouse (Campbell Scientific, United States) comprising a data logger (LoggerNet 4.0) displayed in Figure 2, managed the acquisition of local weather data. The data collected from the local weather station was considered as $1^{\text {st }}$ outdoor parameter. The regional weather data for the above-mentioned coordinates were collected from the Korea meteorological administration office, Seoul, South Korea. That data considered as $2^{\text {nd }}$ outdoor parameter. The present study used both regional weather station data as well as local weather station data for prediction. This 
outdoor parameter 1 and 2 were considered as independent parameters, while indoor temperature and humidity were used as dependent variables for the entire prediction model. Temperature, humidity, temperature - humidity index, and solar radiation intensity data are considered input data sets for this experiment. The data loggers record data every 10 min interval in the period between April 2018 to January 2019; 70\% of the data were used for training, and 30\% used for validation. South Korea has four distinct seasons, which are spring (March-May), summer (June-August), autumn (September-November) and winter (December-February). During the summer period and autumn period the strawberry plants were grown on the experimental greenhouse. Since there is no particular climatic season for rainy or monsoon in the current region, the rainy days were considered based on the regional metrological report. Also, there are no simultaneous rainy days during this both period, so that 5 different days of every season from the validation data sets were considered as the rainy period data sets to find the performance of the model during that particular period. In June (2018), 5 days was selected as a rainy (for summer season) data (from $11^{\text {th }}-15^{\text {th }}$ ). During that period the average air temperature was $21.8^{\circ} \mathrm{C}$ $\left(19^{\circ} \mathrm{C}-27^{\circ} \mathrm{C}\right)$ and the average rainfall of the month was $70.42 \mathrm{~mm}$. For the rainy days model validation in the winter season was considered from November $\left(1^{\text {st }}-5^{\text {th }}\right)$. During that period the average rainfall of the month was $32.9 \mathrm{~mm}$, and the average temperature was $10.9^{\circ} \mathrm{C}\left(8.3^{\circ} \mathrm{C}-12^{\circ} \mathrm{C}\right)$. All neural network models used for this study were designed by using MATLAB (R2018b (Version 9.5), Mathworks, USA) software. Likewise, all other statistical analysis works were done with IBM SPSS Statistics (version 26, IBM, USA) and OriginPro (version 9.0, Originlab, USA) software packages.

\section{Prediction models}

\section{Multiple linear regression (MLR) model}

Regression models develop the relationship between the dependent and independent or response variables involved in the process. Factors such as designing simplicity, comparatively accuracy, and a less amount of input data make the regression model as accessible tools for prediction. The functions of MLR can express by the following (Equation 1),

$$
Y=\beta_{0}+\beta_{1} X_{1}+\beta_{2} X_{2}+\cdots+\beta n X n+\varepsilon
$$

where $\mathrm{Y}$ is the response variable (temperature or humidity), $\beta_{0}, \beta_{1}, \beta_{2} \ldots \beta_{\mathrm{n}}$ - are regression coefficients estimated based on a record of observations, $\varepsilon$ refers to the residual (Braun et al., 2014).

\section{Time series model (ARIMA)}

The autoregressive integrated moving average model (ARIMA) is the most preferred model in recent times used to forecast metrological parameters, especially in the shortterm forecasting area (Murat et al., 2018). The combination of autoregressive (AR) model (p), moving average (MA) model (q) called ARIMA (p, d, q), which is a generalized random walk model. First, the time series is d-differenced to render it stationary. If $d=0$, the observations are modeled directly, and if $d=1$, the differences between consecutive observations are modeled (Patel et al., 2014).

$\mathrm{AR}(\mathrm{p})$ is the relationship between the observation and number of lagged information, which can be expressed by Equation 2, 


$$
X_{t}=C+\sum_{i=1}^{p} \emptyset_{i} x_{t-1}+\varepsilon_{t}
$$

where $X_{t}$ is the autoregressive operator of order $p, C$ is the constant, $\phi_{i}$ refers to the parameter of the model, $\mathrm{x}_{\mathrm{t}}$ is the value that observed at $\mathrm{t}$, and $\varepsilon_{\mathrm{t}}$ stands for random error. The MA (q) model calculates the dependency between an observation and a residual error from a moving average model applied to lag observations. The moving average mathematically expressed by Equation 3,

$$
X_{t}=\varepsilon_{t}+\sum_{i=1}^{q} \theta_{i} \varepsilon_{t-i}
$$

where $\mathrm{X}_{\mathrm{t}}$ is the autoregressive operator of order $\mathrm{q}, \theta_{\mathrm{i}}$ is the parameter of the model, $\varepsilon_{\mathrm{t}}$ is the error term. The combination of the autoregressive and moving average model that expressed in terms of (Equation 4),

$$
Y_{t}=c+\sum_{i=1}^{p} \phi_{i} y_{t-i}+\sum_{j=1}^{q} \theta_{j} \varepsilon_{t-j}
$$

where $Y_{t}$ is the predicted value, $\mathrm{c}$ is the constant, $\phi_{i}$ is the coefficient determined by AR, and $\theta_{i}$ is the determined coefficient of the MA model. The ARIMA model was used as a prediction model to predict the indoor temperature and humidity for the greenhouse.

\section{Multilayered perceptron algorithm}

Multilayered perceptron is one of the commonly used feed-forward layered networks due to its low complexity and its ability to solve the nonlinear criteria. In general, the neural network model is included with various learning adaption techniques. Apart from the input, hidden, and output layer elements, the weights, and bias are the vital elements involved in the process of output layer calculation (Taki et al., 2016). The weights are calculated using the following Equation 5,

$$
Y_{j}=\sum_{i-1}^{n} w_{i j} I_{i}+\beta_{j}
$$

where $Y_{j}$ is the weight values, $I_{i}$ is the input variables, $w_{i j}$ is the weight between input parameters, and neuron $\mathrm{j}$ and $\beta_{\mathrm{j}}$ is the bias. The structure of the network explained in Figure 3.

Next, an activation function is used to generate the output of neurons that is decided according to weight values. Different types of activation functions including log, hyperbolic, exponential, and sigmoid can be used in MLP. The most popular activation function to solve the nonlinear function is sigmoid (Taki et al., 2016), so that the current study used sigmoid as the transfer function of the MLP. The sigmoid transfer function is expressed by Equation 6, 


$$
f(\theta)=\frac{1}{1+e^{-\theta}}
$$

Once each neuron and the transfer functions are calculated, the final output layer which is expressed by the following Equation 7,

$$
y_{k}=\sum_{i=1}^{n} w_{k j} f_{i}+\beta_{k}
$$

The next essential framework for performing any ANN model is training the network. The feed-forward back-propagation network undergoes supervised training, with a finite number of pattern pairs consisting of an input pattern and a desired or target output pattern (Taki et al., 2016). Since the back-propagation technique minimizes the cost error function, it is commonly used for training algorithms for MLP. For this study, MLP with the feed forward-back propagation model network was designed in the MATLAB software with various transfer functions and adaption techniques. The single hidden layer including a sufficient number of neurons is capable of predicting non-linear variables with the desired output. Based on past studies, the single-layered MLR with random combinational neuron models were used in these studies.

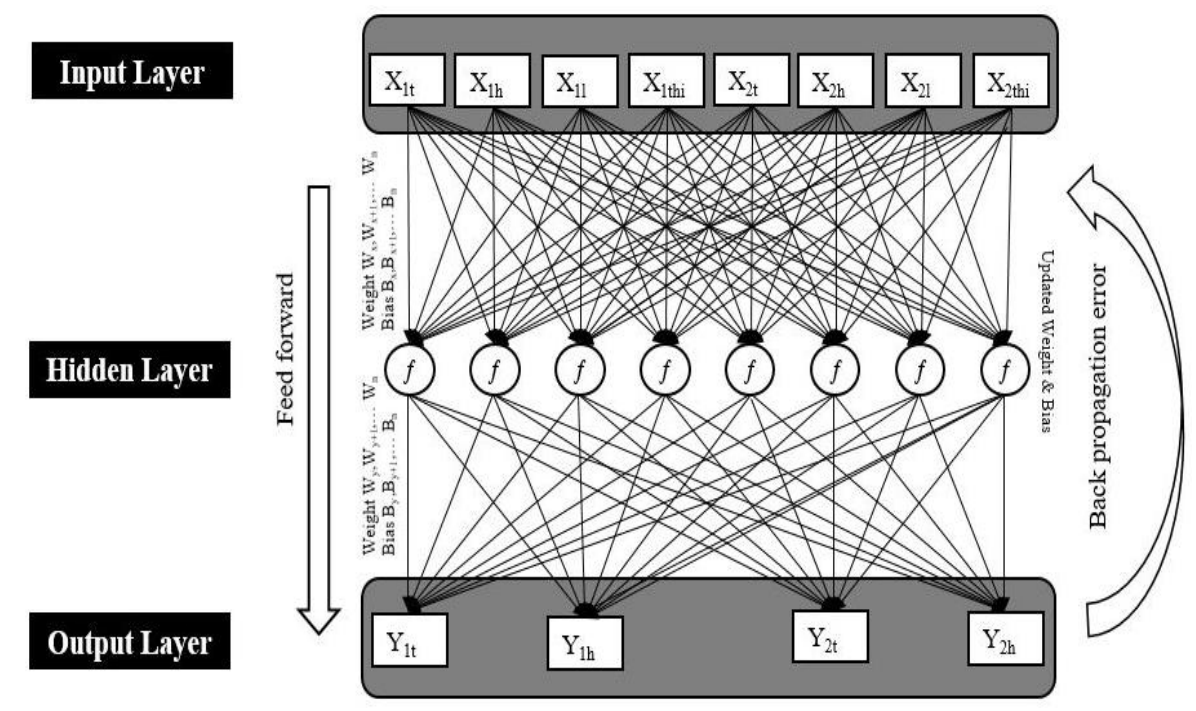

Figure 3. Structure of the MLP with the function of feedforward and backpropagation method

\section{Input and output parameter modeling}

The data were collected from the local weather station and regional weather station data named M1 (local weather station data combined with the regional weather station data), M2 (regional weather station data), and M3 (local weather station data), which were used as the input variables for the prediction. Four dependent variables were predicted (two temperature variables and two humidity variables) by each of the models using M1, M2, and M3 data sets. The comprehensive explanation of the models, as shown in Table 1. These same mixed models used for all of the modeling techniques that are used for the evaluation in this examination. 
Table 1. Input and output variables of $M 1, M 2$, and $M 3$

\begin{tabular}{|c|c|c|}
\hline Model & Input variables & Output variables \\
\hline M1 & $\begin{array}{c}\text { Regional weather station temperature }\left(\mathrm{X}_{1 \mathrm{t}}\right), \\
\text { Regional weather station humidity }\left(\mathrm{X}_{1 \mathrm{~h}}\right), \\
\text { Regional weather station solar intensity }\left(\mathrm{X}_{11}\right), \\
\text { Regional weather station temperature-humidity index }\left(\mathrm{X}_{1 \mathrm{thi}}\right) \text {, } \\
\text { Local weather station temperature }\left(\mathrm{X}_{2 \mathrm{t}}\right), \\
\text { Local weather station humidity }\left(\mathrm{X}_{2 \mathrm{~h}}\right), \\
\text { Local weather station solar intensity }\left(\mathrm{X}_{2 \mathrm{l}}\right), \\
\text { Local weather station temperature-humidity index }\left(\mathrm{X}_{2 \mathrm{thi}}\right)\end{array}$ & $\begin{array}{c}\text { Indoor temperature (front) } \\
\left(\mathrm{Y}_{1 \mathrm{t}}\right), \\
\text { Indoor humidity (front) }\left(\mathrm{Y}_{1 \mathrm{~h}}\right) \text {, } \\
\text { Indoor temperature (back) } \\
\left(\mathrm{Y}_{2 \mathrm{t}}\right), \\
\text { Indoor humidity (back) }\left(\mathrm{Y}_{2 \mathrm{~h}}\right)\end{array}$ \\
\hline M2 & $\left(\mathrm{X}_{1 \mathrm{t}}, \mathrm{X}_{1 \mathrm{~h}}, \mathrm{X}_{11}, \mathrm{X}_{1 \mathrm{thi}}\right)$ & $\left(\mathrm{Y}_{1 \mathrm{t}}, \mathrm{Y}_{1 \mathrm{~h}}\right) \&\left(\mathrm{Y}_{2 \mathrm{t}}, \mathrm{Y}_{2 \mathrm{~h}}\right)$ \\
\hline M3 & $\left(\mathrm{X}_{2 \mathrm{t}}, \mathrm{X}_{2 \mathrm{~h}}, \mathrm{X}_{2 \mathrm{ll}}, \mathrm{X}_{2 \mathrm{thi}}\right)$ & $\left(\mathrm{Y}_{1 \mathrm{t}}, \mathrm{Y}_{1 \mathrm{~h}}\right) \&\left(\mathrm{Y}_{2 \mathrm{t}}, \mathrm{Y}_{2 \mathrm{~h}}\right)$ \\
\hline
\end{tabular}

\section{Model evaluation criteria}

Various statistical indicators were used to evaluate the prediction model. The coefficient of determination can well measure the degree of proximity between the actual data and the predicted values. For a comprehensive evaluation, the results of the models were analyzed by the coefficient of determination $\left(\mathrm{R}^{2}\right)$, the root mean square error (RMSE), the mean square error (MSE) and the mean absolute error (MAE) (Lu and Viljanen, 2009). $\mathrm{R}^{2}$, MAE, RMSE, and MSE can be expressed by the following equations (Equations 8-11),

$$
\begin{gathered}
R^{2}=1-\frac{\sum_{i=1}^{n}\left(y_{i}-p_{i}\right)^{2}}{\sum_{i=1}^{n}\left(y_{i}-\frac{1}{n} \sum_{i=1}^{n} y_{i}\right)^{2}} \\
R M S E=\sqrt{\frac{\sum_{i=1}^{n}\left(y_{i}-p_{i}\right)^{2}}{n}} \\
M S E=\frac{\sum_{i=1}^{n}\left(y_{i}-p_{i}\right)^{2}}{n} \\
M A E=\frac{\sum_{i=1}^{n}\left|y_{i}-p_{i}\right|}{n}
\end{gathered}
$$

\section{Results and discussion}

\section{MLR model results}

The indoor temperature and humidity data were predicted using MLR. As mentioned earlier, stepwise and feed-forward methods were used during the time of testing. Even though the feed-forward method performs very similar to the stepwise approach, the stepwise approach outperforms in predicting the temperature as well as the humidity variables. The overall better performance of the MLR was with M1 in terms of $\mathrm{R}^{2}$ value, and the evaluation results showed in Table 2. MLR prediction has the coefficient of determination 0.955 in M1, while M3 has 0.952 . The least value, which was from M2 
with 0.708 with is $74 \%$ lesser than the higher prediction value. Importantly, MAE was similar in M1 (stepwise) and M3 (both stepwise and feed-forward), which resemble the maximum capacity of both the model. The prediction accuracy of M1 for $\mathrm{Y}_{2 \mathrm{t}}$ lower than the M1 $\left(\mathrm{R}^{2}=0.953\right)$ when compared to M3, but MSE and RMSE were lower in M3, which cannot be ignorable. All three models were predicted the $Y_{2 t}$ lesser than the $Y_{1 t}$. Both M1 and M3 performs well for predicting the temperature variables in MLR modeling with less error with statistical substantiation.

Table 2. Performance of the MLR analysis

\begin{tabular}{|c|c|c|c|c|c|}
\hline Predicted variable & Model & $\mathbf{R}^{2}$ & MAE & MSE & RMSE \\
\hline \multirow{3}{*}{$\mathbf{Y}_{1 \mathrm{t}}$} & M1 & 0.955 & 1.23 & 2.21 & 1.48 \\
\hline & M2 & 0.708 & 2.36 & 9.29 & 3.04 \\
\hline & M3 & 0.952 & 1.24 & 2.21 & 1.48 \\
\hline \multirow{3}{*}{$\mathbf{Y}_{2 t}$} & M1 & 0.953 & 1.21 & 2.16 & 1.47 \\
\hline & M2 & 0.682 & 2.41 & 9.80 & 3.13 \\
\hline & M3 & 0.950 & 1.18 & 2.04 & 1.42 \\
\hline \multirow{3}{*}{$\mathbf{Y}_{1 \mathrm{~h}}$} & M1 & 0.832 & 6.12 & 57.66 & 7.59 \\
\hline & M2 & 0.544 & 8.74 & 159.56 & 12.63 \\
\hline & M3 & 0.823 & 8.44 & 122.85 & 11.08 \\
\hline \multirow{3}{*}{$\mathbf{Y}_{2 \mathrm{~h}}$} & M1 & 0.824 & 6.85 & 72.66 & 8.52 \\
\hline & M2 & 0.524 & 9.73 & 201.48 & 14.1 \\
\hline & M3 & 0.812 & 10.0 & 167.36 & 12.93 \\
\hline
\end{tabular}

In the case of humidity prediction, the results were clearly announcing the M1 predictions are better than the other two in terms of all model evaluation criteria. The overall performance ranking of the models for humidity prediction results was the same as the temperature prediction ranking of the models, accordingly M1, M3, and M2 (least). The difference between the highest and lowest performance was $71 \%$ in $\mathrm{Y}_{1 \mathrm{~h}}$ prediction modeling in terms of $\mathrm{R}^{2}$. Overall, the maximum $\mathrm{R}^{2}$ of $\mathrm{Y}_{1 \mathrm{~h}}$ was 0.832 , which was obtained in $\mathrm{M} 1$ with $\mathrm{MAE}=6.12$ and $\mathrm{RMSE}=7.59$. In $\mathrm{Y}_{2 \mathrm{~h}}$ prediction, $\mathrm{MAE}$ and RMSE were high in both M3 and M2, unlike temperature prediction, especially in M2. More detailed prediction curve, as shown in Figure 4. However, the following key points were observed during MLR model evaluation,

- Even though the M1 and M3 performance was similar, M1 successfully helps to make predictions better than the M3.

- Unlike the prediction of temperature variables, the prediction of the humidity variables is less in terms of correlation and evaluation. The detailed results of the MLR models are shown in Table 2.

\section{ARIMA model results}

The mixed autoregressive and moving average (ARIMA) model prediction performance results shown in Table 3. The better performance of predicting $\mathrm{Y}_{1 \mathrm{t}}$ with M1 has $\mathrm{R}^{2}=0.959, \mathrm{MAE}=0.9$, and $\mathrm{RMSE}=1.16$, followed by $\mathrm{M} 3\left(\mathrm{R}^{2}=0.95\right)$. Even though both M1 and M3 have a similar coefficient of determination but MAE and RMSE were high in $\mathrm{M} 3 . \mathrm{Y}_{2 \mathrm{t}}$ resembled the pattern of $\mathrm{Y}_{1 \mathrm{t}}$ prediction, MAE and RMSE were higher in M1 than the M3. Anywhere of the model, M2 does not over $70 \%$ in terms of $\mathrm{R}^{2}$ value for both temperature and humidity variable predictions also MSE, and RMSE was very high from the other two models. Since this experiment uses the moving average model, the model 
fits according to the different percentile of the full data set. From the observations, temperature variables fit was the same in all percentile, whereas humidity fit was low at the initial time, and gradually it increases and after 50 percentile. For instance, $\mathrm{Y}_{1 \mathrm{~h}}$ 's $\mathrm{R}^{2}$ was 0.818 in 5 percentile, and it gradually increases up to 70 percentile and its reach to the maximum best fit by the model 0.838 . Not only $\mathrm{R}^{2}$, MAE, and RMSE also been adjusted after percentile of data changes. For M1 obtained $\mathrm{Y}_{2 \mathrm{~h}}$ prediction bet fit with 0.821 followed by M3 with 0.796 . However, this model was performed well against temperature prediction; nevertheless, humidity predictions have low efficient performance.

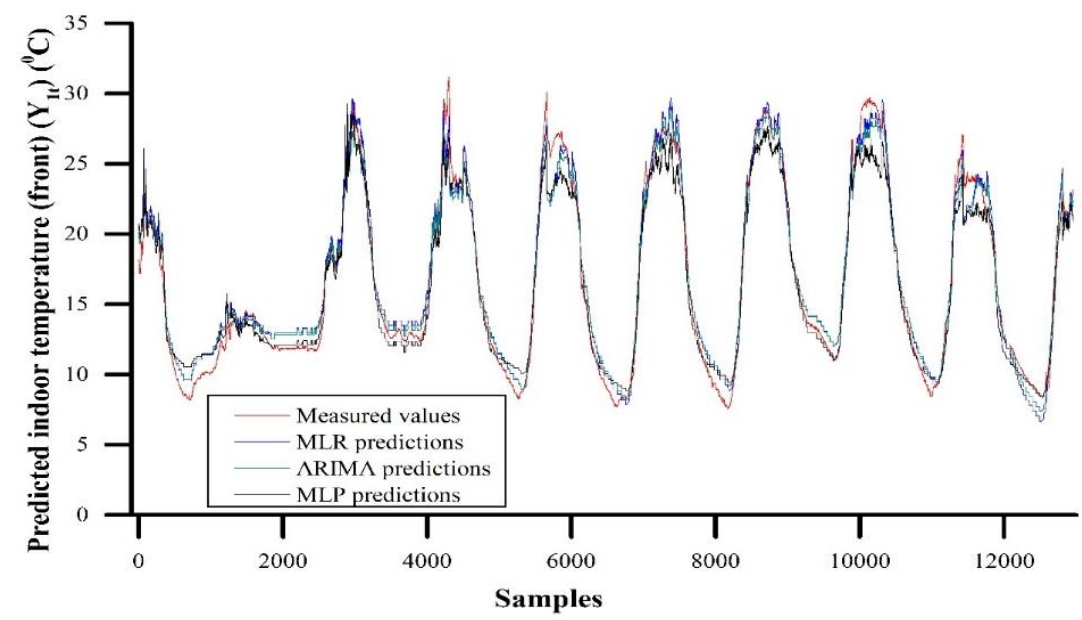

Figure 4. Comparison of actual data and predicted indoor temperature (front) $\left(Y_{I t}\right)$ by MLR, ARIMA and MLP models

Table 3. Performance of the time series model analysis

\begin{tabular}{c|c|c|c|c|c}
\hline Prediction variable & Model & $\mathbf{R}^{\mathbf{2}}$ & MAE & MSE & RMSE \\
\hline \multirow{2}{*}{$\mathbf{Y}_{\mathbf{1 t}}$} & $\mathbf{M 1}$ & 0.959 & 0.90 & 1.35 & 1.16 \\
& $\mathbf{M 2}$ & 0.665 & 2.68 & 11.20 & 3.34 \\
& $\mathbf{M 3}$ & 0.958 & 0.92 & 1.41 & 1.19 \\
\hline \multirow{3}{*}{$\mathbf{Y}_{\mathbf{2 t}}$} & $\mathbf{M 1}$ & 0.953 & 0.92 & 1.45 & 1.20 \\
& $\mathbf{M 2}$ & 0.641 & 2.69 & 11.20 & 3.34 \\
& $\mathbf{M 3}$ & 0.952 & 0.94 & 1.50 & 1.22 \\
\hline \multirow{2}{*}{$\mathbf{Y}_{\mathbf{1 h}}$} & $\mathbf{M 1}$ & 0.838 & 5.90 & 54.96 & 7.41 \\
& $\mathbf{M 2}$ & 0.656 & 8.30 & 116.76 & 10.80 \\
& $\mathbf{M 3}$ & 0.818 & 6.16 & 61.77 & 7.86 \\
\hline \multirow{2}{*}{$\mathbf{Y}_{\mathbf{2 h}}$} & $\mathbf{M 1}$ & 0.821 & 6.75 & 73.97 & 8.60 \\
& $\mathbf{M 2}$ & 0.631 & 9.43 & 152.22 & 12.33 \\
& $\mathbf{M 3}$ & 0.796 & 7.25 & 83.92 & 9.16 \\
\hline
\end{tabular}

\section{MLP model results}

A multilayered perceptron feed-forward network with a back-propagation training algorithm was developed to predict the desired variables. The back propagation-training algorithm based on the Levenberg-Marquardt (LM) was used to simulate the prediction with more optimization. The transfer function used for this MLP was sigmoid since the desirable variables follow the sigmoid pattern. Still, there is a lack of detailed information 
regards fixing the hidden neurons, and this examination used random increasing neurons that start from minimum elements. All the random neuron combination results were referred to as Table 4. The training algorithm randomly generated bias and weight during this examination. For $\mathrm{Y}_{1 \mathrm{t}}$ prediction, M3 (5 neurons) has the highest performance that is with $\mathrm{R}^{2}=0.9793$; MAE $=0.85$; RMSE $=1.21$ followed by the M3 (15 neurons). In M3 prediction, most of the validation gives better results than the M1 model in terms of $\mathrm{R}^{2}$. All combinations of M3 have more than $0.96 \mathrm{R}^{2}$ values, whereas M1 result from 0.91 to 0.97 . The highest evaluation criteria results obtained by M1 was with 20 neurons. Results of $\mathrm{Y}_{2 \mathrm{t}}$ resemble the same pattern as $\mathrm{Y}_{1 \mathrm{t}}$; M3 model performs a higher than the M1. The top prediction of $\mathrm{Y}_{2 \mathrm{t}}$ variable in terms of $\mathrm{R}^{2}=0.974$ obtained in $\mathrm{M} 3$ (30 neurons) with $\mathrm{MAE}=1.04$; nevertheless, M1 prediction has the lowest MAE and RMSE values (MAE=0.95; $\mathrm{RMSE}=1.3 ; \mathrm{R}^{2}=0.966$ ) which could not negligible while consider for modeling. The least performance from the M2 models, which are extremely lower when compared to the other two models. Therefore overall performance shows that the M3 has a high $\mathrm{R}^{2}$, and $\mathrm{M} 1$ has a lower number of error values.

Table 4. Performance of the MLP model analysis with various neuron combinations

\begin{tabular}{|c|c|c|c|c|c|c|}
\hline $\begin{array}{c}\text { Prediction } \\
\text { variable }\end{array}$ & Model & $\begin{array}{l}\text { Hidden } \\
\text { neurons }\end{array}$ & $\mathbf{R}^{2}$ & MAE & MSE & RMSE \\
\hline \multirow{9}{*}{$Y_{1 t}$} & \multirow{3}{*}{ M1 } & 20 & 0.9732 & 0.90 & 1.64 & 1.28 \\
\hline & & 25 & 0.9681 & 0.94 & 1.61 & 1.27 \\
\hline & & 30 & 0.9674 & 0.93 & 1.47 & 1.21 \\
\hline & \multirow{3}{*}{ M2 } & 35 & 0.6698 & 4.79 & 31.97 & 5.65 \\
\hline & & 45 & 0.7574 & 3.75 & 20.75 & 4.55 \\
\hline & & 20 & 0.972 & 1.05 & 1.93 & 1.39 \\
\hline & \multirow{3}{*}{ M3 } & 5 & 0.9793 & 0.85 & 1.47 & 1.21 \\
\hline & & 45 & 0.9764 & 0.95 & 1.72 & 1.31 \\
\hline & & 50 & 0.9756 & 1.15 & 2.21 & 1.48 \\
\hline \multirow{9}{*}{$\mathbf{Y}_{2 t}$} & \multirow{3}{*}{ M1 } & 30 & 0.9609 & 0.96 & 1.84 & 1.35 \\
\hline & & 35 & 0.966 & 0.95 & 1.71 & 1.30 \\
\hline & & 40 & 0.961 & 0.97 & 1.84 & 1.35 \\
\hline & \multirow{3}{*}{ M2 } & 5 & 0.7125 & 4.86 & 33.29 & 5.77 \\
\hline & & 20 & 0.6065 & 5.18 & 38.54 & 6.20 \\
\hline & & 50 & 0.6267 & 4.53 & 29.77 & 5.45 \\
\hline & \multirow{3}{*}{ M3 } & 30 & 0.974 & 1.04 & 1.92 & 1.32 \\
\hline & & 35 & 0.97 & 1.00 & 1.96 & 1.40 \\
\hline & & 40 & 0.966 & 1.12 & 2.32 & 1.52 \\
\hline \multirow{9}{*}{$Y_{1 h}$} & \multirow{3}{*}{ M1 } & 5 & 0.9093 & 4.72 & 39.73 & 6.30 \\
\hline & & 10 & 0.7822 & 8.36 & 128.30 & 11.32 \\
\hline & & 35 & 0.8592 & 6.40 & 80.35 & 8.96 \\
\hline & \multirow{3}{*}{ M2 } & 15 & 0.5072 & 14.54 & 461.44 & 21.48 \\
\hline & & 20 & 0.4131 & 16.67 & 516.20 & 22.72 \\
\hline & & 45 & 0.664 & 13.86 & 362.69 & 19.04 \\
\hline & \multirow{3}{*}{ M3 } & 5 & 0.8574 & 6.88 & 81.39 & 9.02 \\
\hline & & 15 & 0.8316 & 6.87 & 79.90 & 8.93 \\
\hline & & 20 & 0.8375 & 7.23 & 88.88 & 9.42 \\
\hline \multirow{9}{*}{$\mathbf{Y}_{2 h}$} & \multirow{3}{*}{ M1 } & 5 & 0.8151 & 7.66 & 119.88 & 10.94 \\
\hline & & 10 & 0.8116 & 7.956 & 124.39 & 11.15 \\
\hline & & 40 & 0.8154 & 7.876 & 121.02 & 11.00 \\
\hline & \multirow{3}{*}{ M2 } & 25 & 0.4383 & 17.19 & 465.99 & 21.58 \\
\hline & & 40 & 0.5048 & 16.05 & 421.49 & 20.53 \\
\hline & & 45 & 0.5498 & 15.47 & 422.62 & 20.50 \\
\hline & \multirow{3}{*}{ M3 } & 5 & 0.804 & 7.98 & 123.02 & 11.09 \\
\hline & & 40 & 0.771 & 9.18 & 202.47 & 14.22 \\
\hline & & 45 & 0.802 & 8.76 & 130.24 & 11.41 \\
\hline
\end{tabular}


For $\mathrm{Y}_{1 \mathrm{~h}}$ predictions, M1 (5 neurons) has the highest $\mathrm{R}^{2}(0.9093)$ among all other combinations with lower error values $\mathrm{MAE}=4.72$ and $\mathrm{RMSE}=6.30$ followed by 35 neurons set $\left(\mathrm{R}^{2}=0.8592\right.$; $\mathrm{MAE}=6.40$; $\left.\mathrm{RMSE}=8.96\right)$ in $\mathrm{M} 1$. The top prediction of M3 obtained from 40-neuron combination, but the error values higher than the second and third highest predicted combinations. Prediction results for the $\mathrm{Y}_{2 \mathrm{~h}}$ have the highest in M1 (40 neurons) in terms of $\mathrm{R}^{2}$ was 0.8154 , whereas 5 neuron prediction has the lowest $\mathrm{MAE}=7.66$ also it has the least RMSE value. Other than the 5, 10 and 40 neuron combinations, all M1 combinations were performed poor in terms of correlation and determination. The overall results of this model explain that neurons not linearly related to the performance. Maximum iteration was observed during both testing, and crossvalidation period was 1000 , whereas 400 iteration was the minimum. During the time of making the neuron combination randomly, other neurons combinations also have been tested, for instance, in between to the 5-10 combinations indiscriminately 6 or 7 also used to avoid the lesser accuracy. However, the random test results were not accurate than the highest prediction so that the random combination results not shown in Table 4.

\section{Compression between MLR, ARIMA and MLP models}

Previous studies prove that traditional statistical models are potential tools for predicting the environmental parameters in a more precise manner (Mehdi et al., 2013); also, several studies developed a high accurate computational model for the prediction (Taki et al., 2015; Shi et al., 2018). According to this results the highest accuracy of predicted values $\mathrm{Y}_{1 \mathrm{t}}$ for MLR, ARIMA and MLP accordingly $0.955 ; 1.23 ; 2.21 ; 1.48\left(\mathrm{R}^{2}\right.$; MAE; MSE; RMSE), 0.959; 0.90; $1.35 ; 1.16$ and $0.9793 ; 0.85 ; 1.47 ; 1.21$. For the $\mathrm{Y}_{1 \mathrm{t}}$ prediction, the MLP model has a higher $\mathrm{R}^{2}$ and MSE, whereas ARIMA performed well in terms of RMSE and the MAE. MLR has two methods that are stepwise and feedforward, and MLP has varied the combination of neurons. So according to the variable $Y_{1 t}$ MLP model prediction with 5-neuron combination doing the best performance in this examination. $\mathrm{Y}_{2 \mathrm{t}}$ best predictions in MLR, ARIMA and MLP model as follows 0.954; $1.20 ; 2.14 ; 1.46$ (R²; MAE; MSE; RMSE), 0.952; 0.94; 1.50; 1.22 and 0.974; $1.04 ; 1.92$; 1.32. Even though $\mathrm{R}^{2}$ is higher in the MLP model, ARIMA has the lower MAE, MSE and RMSE values that could not be ignored. Unlike temperature prediction, all three models have some limitations while simulating the humidity variables. M1 and M3 performed well during the temperature prediction in any prediction model, whereas for the humidity predictions, M1 help to improve the accuracy of each model. Most of the time, the highest number neurons combination fails to predict the humidity during MLP simulations and their error values were high when the neurons increased. The performance of MLP was $0.9093 ; 4.72 ; 39.73 ; 6.30$ ( $\mathrm{R}^{2}$; MAE; MSE; RMSE), other than this model, no other model has no closer output to this model. $0.832 ; 6.12 ; 57.66 ; 7.59$ was the performance of M1 in MLR and $0.838 ; 5.9 ; 54.96 ; 7.41$ was obtained by the ARIMA. In between the 1000-2000 samples, all the models predicted beyond the limit and at these values impacted most in prediction. All these model performance graphs were displayed in Figures 4-7.

In $\mathrm{Y}_{2 \mathrm{~h}}$ predictions MLR model performs better than the other models with the 0.824 ; 6.85; 72.66; 8.52 (R²; MAE; MSE; RMSE) followed by the MLP 0.8154; 7.87; 121.02; 11.00. The predicted value graph shown in Figure 7, particularly at some point in time, the humidity value reached the maximum level, in that cases other than the MLR does not predict the changes. While observing the curves, MLP follows the same pattern but predicted more than the actual peak times. The overall performance of the MLP model 
was better than the other models except for $\mathrm{Y}_{2 \mathrm{~h}}$ predictions in terms of $\mathrm{R}^{2}$ and error values. The validation results with the post-regression model fit in the sense of $\mathrm{R}^{2}$ shown in Figure 8, though $\mathrm{Y}_{2 \mathrm{t}}$ has some distinguished data scattering, $\mathrm{Y}_{1 \mathrm{t}}$ and $\mathrm{Y}_{2 \mathrm{t}}$ measured data were not much distributed, and it lies on the same level. The effects of non-normalized real-time data visible in evidence of $\mathrm{Y}_{1 \mathrm{~h}}$ and $\mathrm{Y}_{2 \mathrm{~h}}$ regression from Figure 8. From the analysis, error validation, and $\mathrm{R}^{2}$, the MLP performs higher than the other models used in this literature.

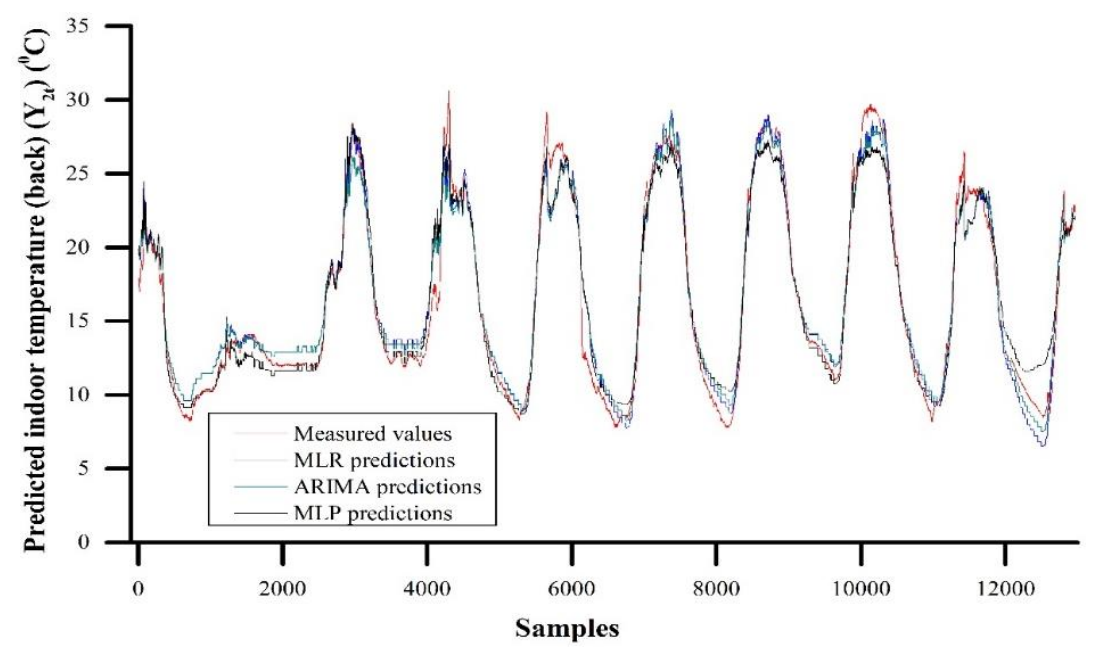

Figure 5. Comparison of actual data and predicted indoor temperature (back) $\left(Y_{2 t}\right)$ by MLR, ARIMA and MLP models

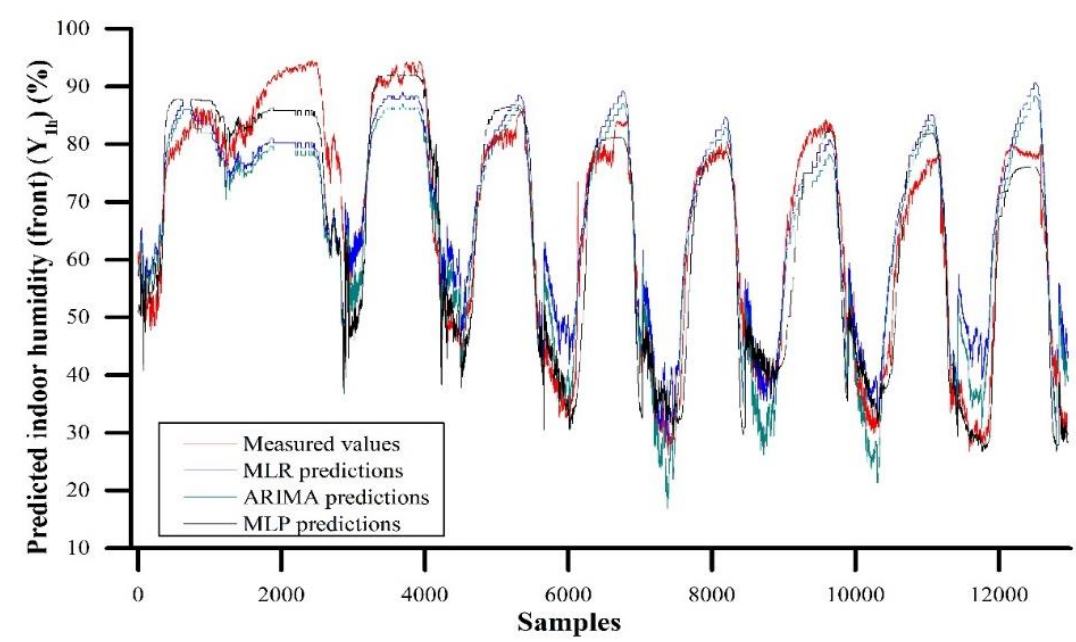

Figure 6. Comparison of actual data and predicted indoor humidity (front) $\left(Y_{l h}\right)$ by MLR, ARIMA and MLP models

\section{Seasonal based appraisal}

According to the model evaluation results, the authentic resulted models were subjected to the seasonal based intensive test. The predicted data sets were separated according to the four seasons, and the results were appraised with the same evaluation criteria which are used for the whole year data sets. From the seasonal based analysis 
results during the spring period, for $\mathrm{Y}_{1 \mathrm{t}}$ prediction the MLP model outperformed $\left(\mathrm{R}^{2}\right.$; MAE; MSE; RMSE: $0.9589 ; 0.971 ; 1.765 ; 1.328)$ followed by the ARIMA $(0.948 ; 1.111$; $2.378 ; 1.542)$. In $Y_{2 t}$ predictions, the ARIMA performed better $\mathrm{R}^{2}(0.8858)$ than the MLR (0.8768) model, based on the other criteria (MAE; MSE; RMSE) the MLR model have the lower mean error values $(1.067 ; 2.23 ; 1.494)$ than the ARIMA model $(1.34 ; 2.981$; 1.726). In terms of $R^{2}$ values the ARIMA model followed by the MLP model (0.8814). For the $\mathrm{Y}_{1 \mathrm{~h}}$ variable MLP performed better prediction $\left(\mathrm{R}^{2}=0.8447\right)$ which was followed by the ARIMA $\left(R^{2}=0.7989\right)$. MLP has the highest $R^{2}(0.7843)$ for $Y_{2 h}$ among all models. Likewise, for all four seasons the most of MLP prediction has a good correlation with the measured temperature variables (autumn season $\mathrm{R}^{2}$ for MLP $\left(\mathrm{Y}_{1 \mathrm{t}}=0.9589\right)$, summer season $\mathrm{R}^{2}\left(\mathrm{Y}_{1 \mathrm{t}}=0.8143 ; \mathrm{Y}_{2 \mathrm{t}}=0.829\right)$, winter season $\left.\mathrm{R}^{2}\left(\mathrm{Y}_{1 \mathrm{t}}=0.8432 ; \mathrm{Y}_{2 \mathrm{t}}=0.8372\right)\right)$. Even though, in spring season $\mathrm{Y}_{2 t}$ prediction performed well in ARIMA $\left(\mathrm{R}^{2}=0.8858\right.$; $\mathrm{MAE}=1.348 ; \mathrm{RMSE}=1.726)$ followed by $\operatorname{MLP}\left(\mathrm{R}^{2}=0.8814 ; \mathrm{MAE}=1.215 ; \mathrm{RMSE}=1.653\right)$ in terms of MAE and RMS values the MLR has the lower errors $\left(\mathrm{R}^{2}=0.8768\right.$; $\mathrm{MAE}=1.067 ; \mathrm{RMSE}=1.494$ ). Apart from spring season $\mathrm{Y}_{2 \mathrm{t}}$ prediction MLP outperformed in temperature prediction followed by ARIMA.

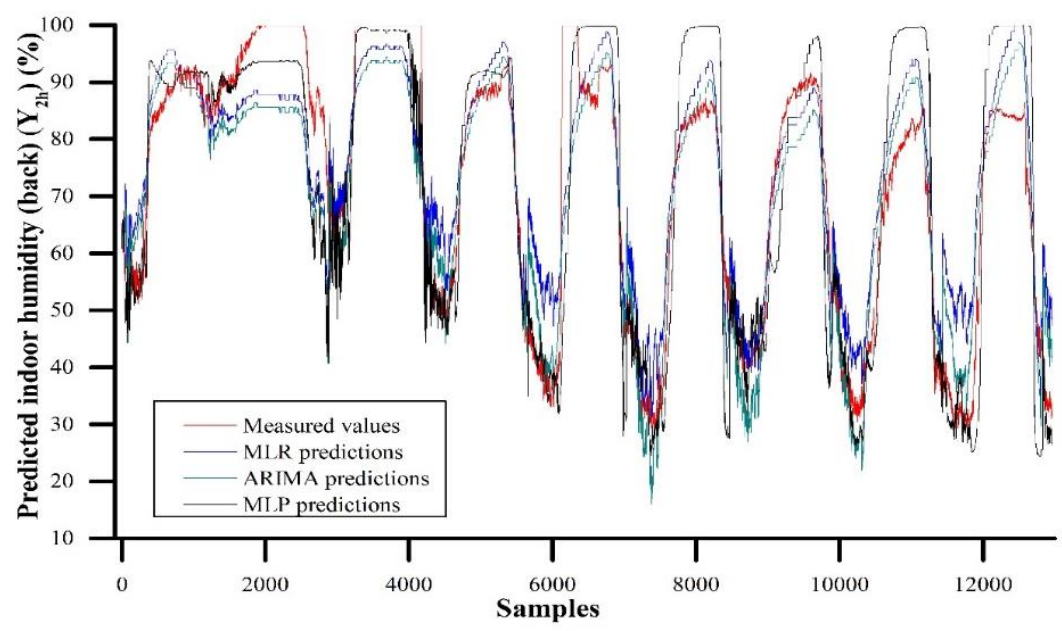

Figure 7. Comparison of actual data and predicted indoor humidity (back) $\left(Y_{2 h}\right)$ by $M L R$, ARIMA, and MLP models

Unlike temperature predicted data, the humidity predicted variables relationship with measured values was uncertain in MLR and ARIMA. The pattern of humidity prediction results resembles the prediction model results. In all the four seasons, MLP achieved better results (spring season results for MLP $\left(\mathrm{Y}_{1 \mathrm{~h}}: \mathrm{R}^{2}=0.8447\right.$; $\mathrm{MAE}=4.568$; $\left.\mathrm{RMSE}=6.378 ; \mathrm{Y}_{2 \mathrm{~h}}: \mathrm{R}^{2}=0.7843 ; \mathrm{MAE}=5.136 ; \mathrm{RMSE}=7.539\right)$, summer season results $\left(\mathrm{Y}_{1 \mathrm{~h}}: \quad \mathrm{R}^{2}=0.845 ; \quad \mathrm{MAE}=5.150 ; \quad \mathrm{RMSE}=7.187 ; \quad \mathrm{Y}_{2 \mathrm{~h}}: \quad \mathrm{R}^{2}=0.7026 ; \quad \mathrm{MAE}=7.052 ;\right.$ $\mathrm{RMSE}=9.588)$, autumn season results $\left(\mathrm{Y}_{1 \mathrm{~h}}: \mathrm{R}^{2}=0.9040 ; \mathrm{MAE}=4.827 ; \mathrm{RMSE}=6.446 ; \mathrm{Y}_{2 \mathrm{~h}}\right.$ : $\left.\mathrm{R}^{2}=0.8764 ; \quad \mathrm{MAE}=6.935 ; \mathrm{RMSE}=9.045\right)$ winter season results $\left(\mathrm{Y}_{1 \mathrm{~h}}: \mathrm{R}^{2}=0.631\right.$; $\left.\mathrm{MAE}=4.202 ; \mathrm{RMSE}=4.930 ; \mathrm{Y}_{2 \mathrm{~h}}: \mathrm{R}^{2}=0.471 ; \mathrm{MAE}=5.976 ; \mathrm{RMSE}=7.868\right)$ ). Even though, the MEA and RMSE values were less when compared with total prediction model results, the $\mathrm{R}^{2}$ values are less in seasonal based analysis. Especially in the winter season humidity prediction performed less among the all seasons. Moreover the prediction accuracy was higher than the overall all prediction during the autumn season. The coefficient of 
determination values displayed in the Figure 9 to understand the model prediction accuracy in a comparative manner.

The cumulative validation results of all the three models for the rainy days in winter and summer displayed in Figure 10. Among these rainy days' validation, the winter season prediction was better in MLP for temperature and humidity data $\left(\mathrm{Y}_{1 \mathrm{t}}: \mathrm{R}^{2}=0.8773\right.$; MAE $=0.351 ; \quad \mathrm{RMSE}=0.488 ; \quad \mathrm{Y}_{2 \mathrm{t}}: \quad \mathrm{R}^{2}=0.7475 ; \quad \mathrm{MAE}=0.940 ; \quad \mathrm{RMSE}=1.000 ; \quad \mathrm{Y}_{1 \mathrm{~h}}$ : $\mathrm{R}^{2}=0.9062 ; \mathrm{MAE}=1.475 ; \mathrm{RMSE}=2.919 ; \mathrm{Y}_{2 \mathrm{~h}}: \mathrm{R}^{2}=0.7413$; MAE=6.852; RMSE 6.976) followed by the ARIMA model performed better than MLR. When compared to the entire winter season results the rainy days' prediction has better $\mathrm{R}^{2}$ values especially for the humidity variables. The humidity predictions were more reliable in MLR models when compared to other models. Even though the ARIMA model has a higher $\mathrm{R}^{2}\left(\mathrm{Y}_{1 \mathrm{t}}=0.8071\right.$; $\left.Y_{2 t}=0.763\right)$ then the MLR $\left(Y_{1 t}=0.7927 ; Y_{2 t}=0.7603\right)$ model in $Y_{1 t}$ and $Y_{2 t}$ predictions, the MAE and RMSE were less in MLR ( $\mathrm{Y}_{1 \mathrm{t}} ; \mathrm{MAE}=0.812 ; \mathrm{RMSE}=1.143: \mathrm{Y}_{2 \mathrm{t}} ; \mathrm{MAE}=1.320$; RMSE=1.863) than ARIMA ( $Y_{1 \mathrm{t}} ; \mathrm{MAE}=0.868 ; \mathrm{RMSE}=1.251: \mathrm{Y}_{2 \mathrm{t}} ; \mathrm{MAE}=1.526$; RMSE=2.085). Apart from that, the overall MLP predictions were surpassed than other models.
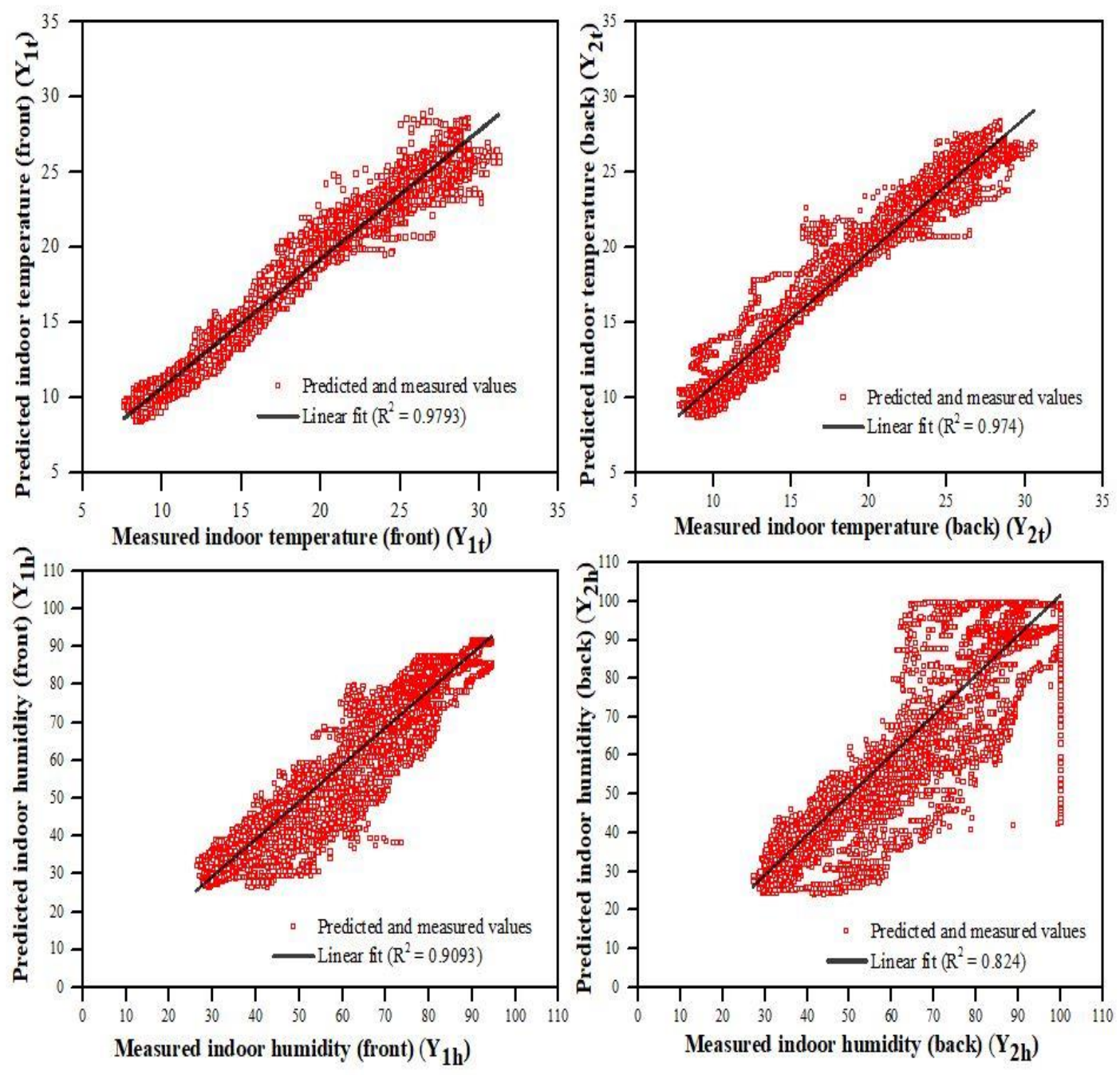

Figure 8. Post-Regression results between predicted data and measured data of the MLP model $\left(Y_{l t}, Y_{2 t}, Y_{l h}\right.$, and $\left.Y_{2 h}\right)$ 

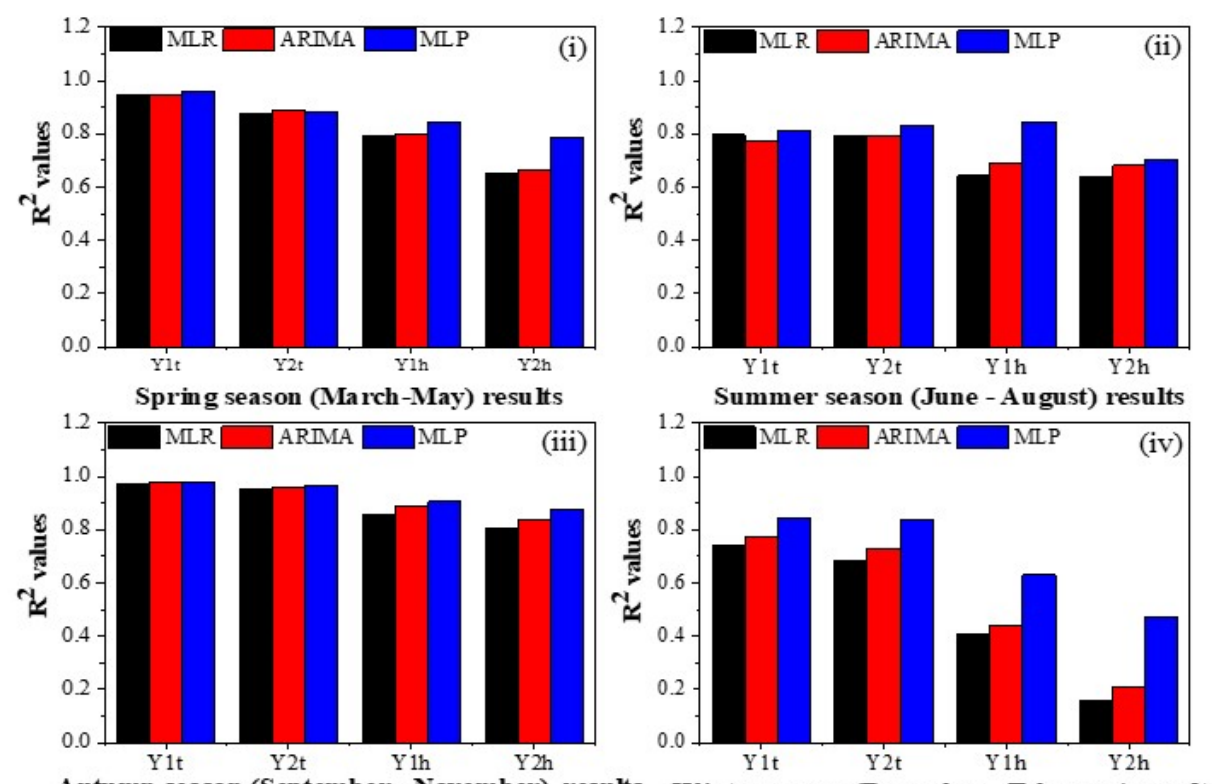

Figure 9. The coefficient of determination $\left(R^{2}\right)$ between measured and predicted values of all three models for (i) Spring season, (ii) Summer season, (iii) Autumn season, and (iv) Winter season

\section{Discussion}

\section{Prediction model}

The present study predicted the temperature and humidity of a greenhouse with different approaches. The MLR models are simple and easy to handle; likewise the MLR predicts the temperature variables similar to the other models. Apart from the temperature variables, the MLP (computational model) performs better than the other models. It seems that the scenario of extrapolating beyond the range of the data, regression models face limitations to perform well; it decreases the model reliability. Though several studies developed a prediction model for greenhouse temperature prediction (Lu and Viljanen, 2009), the indoor humidity prediction with neural network models are lacking in literature due to its more complicated mechanism involved that depends on thermal behaviors or temperature prediction. Leopold et al. (2016) developed a neural network model to predict the indoor temperature and humidity with the Indoor temperature $\left(\mathrm{R}^{2}=0.970\right)$ and indoor humidity $\left(\mathrm{R}^{2}=0.694\right)$. The current study MLP model performed better than the literature mentioned above, in both temperature $1\left(R^{2}=0.9793\right)$, temperature $2\left(R^{2}=0.974\right)$, humidity $1\left(\mathrm{R}^{2}=0.9093\right)$ and humidity $2\left(\mathrm{R}^{2}=0.8154\right)$ prediction. However, the previous study used more input parameters with a large number of parameters; our model performed well with less number of input variables. Previous studies used different input factors to train their model for the highest accuracy, since the variables may affect by the indoor microclimatic condition such as wind speed, solar radiation, soil moisture, rainfall, etc. (Lu and Viljanen, 2009; Choab et al., 2019). For instance, Taki et al. (2015) predicted the greenhouse indoor room temperature from 9 input parameters, and that study has the $\mathrm{R}^{2}$ of 0.9941 , which is higher than the current study $\left(R^{2}=0.9793\right)$. However, the complexity of the prediction model increased if there are several input parameters while comparing it to our model is simpler than his model. Besides, his study conducted only on indoor 
temperature, not on indoor humidity. Preparation of data sets, preprocessing and normalizing the input data techniques are involved in mapping the data linearly over a specific range that increases the accuracy of the model. Particularly in models that used with neurons, the activation function can be performed within the limited range of values so that normalized data which ranges from $[0,1]$ can able to produce meaningful results during the neural network performance (Jayalakshmi and Santhakumaran, 2011; Taki et al., 2015). For instance, Shi et al. (2018) study designed a model for prediction of indoor temperature and relative humidity based on the cloud database by using a backpropagation neural network model. Unlike current literature, that model used improved techniques to train the network. However, that model accuracy was higher than our study (indoor temperature $\mathrm{R}^{2}=0.974$ and indoor humidity $\mathrm{R}^{2}=0.917$ ), the authors have mentioned that the preprocessing of the data during the training time increases the complexity of the model and the simulation time though the accuracy is improved. Our current model has no such kind of limitations including the training and stimulation time since the input variables were limited. This research has done with the aim that not only concluded with robustness and capability of various prediction model; also the extension of this research is to implement the high accuracy model in real-time control devices for the greenhouse control strategy. The current research prompted to analyze without modifying the data that was collected from cloud and sensors so that the entire study utilizes the actual data as the input to train the model also the model validation also conducted in the real-time datasheet. The strawberry plants were grown in the greenhouse during the time of the experiment, and it may affect the humidity very much. Rather than the temperature, humidity can easily be affected by many ways like change in rain amount and ventilation rate of the greenhouse, which are unfortunately not included as input parameters in this research, such limitation predicted both two indoor humidity parameters as a challenging factor (Lu and Viljanen, 2009). The deviation between the affected data and predicted data for especially in humidity prediction is inevitable, which needs attention while these models implement in real-time. When compared to the MLR and ARIMA, MLP learns the distribution of the data in a short period. The seasonal based analysis affirms that the MLP has surpassed performance than other models. Even though the country located in the temperate zone in geographical aspects, the wider temperature difference between summer and winter (much precipitation also occurs during both seasons) made the predictions as an intricate methodology. So that a quickly adaptable algorithm can able to fulfill the short time predictions as the desired manner. Most importantly, while talking about real-time implementation, predicting time is also a decisive factor. This current study MLP model performs quickly than the other models since the input parameters are well formulated.

\section{Input variable model}

By comparing M1, M2, and M3 models after post prediction analysis, most of the time M1 (local weather station data combined with the regional weather station data) helps to get more accuracy. During the time of temperature prediction ( $Y_{1 t}$ and $\left.Y_{2 t}\right), M 3$ performs better among the models used for this research. For instance, during the $\mathrm{Y}_{1 \mathrm{t}}$ prediction, best performance of M3 $0.64 \%$ higher than the M1's best performance by $\mathrm{R}^{2}$ comparison and $0.83 \%$ higher during $\mathrm{Y}_{2 \mathrm{t}}$ predictions. For $\mathrm{Y}_{1 \mathrm{~h}}$ prediction, the M1's highest performance $6.05 \%$ higher than the M3's best performance and $1.48 \%$ higher during $\mathrm{Y}_{2 \mathrm{~h}}$ prediction in terms of $\mathrm{R}^{2}$ values. While comparing the MAE and RMSE value, during the time of $\mathrm{Y}_{1 \mathrm{~h}}, \mathrm{M} 1$ has $31 \%$ of lesser MAE and 34\% of less RMSE values than the M3 model 
also in $\mathrm{Y}_{2 \mathrm{~h}}$ prediction M1 has $31 \%$ of lesser MAE and 30\% less RMSE than M3. Since the eccentricity between the predicted values and measured values, especially in cases of humidity predictions, these deviations unable to ignored or negligible. The individual performance of the regional weather station data is not up to the mark in this indoor microclimatic prediction, and it performs well if combined with local weather station data. The foremost point of every forecast is to obtain the maximum accuracy prediction so that the addition of regional weather station data has driven the model to higher performance than the normal one, though it was without undergoing any modified with optimized statistical methods such as normalization and sampling.
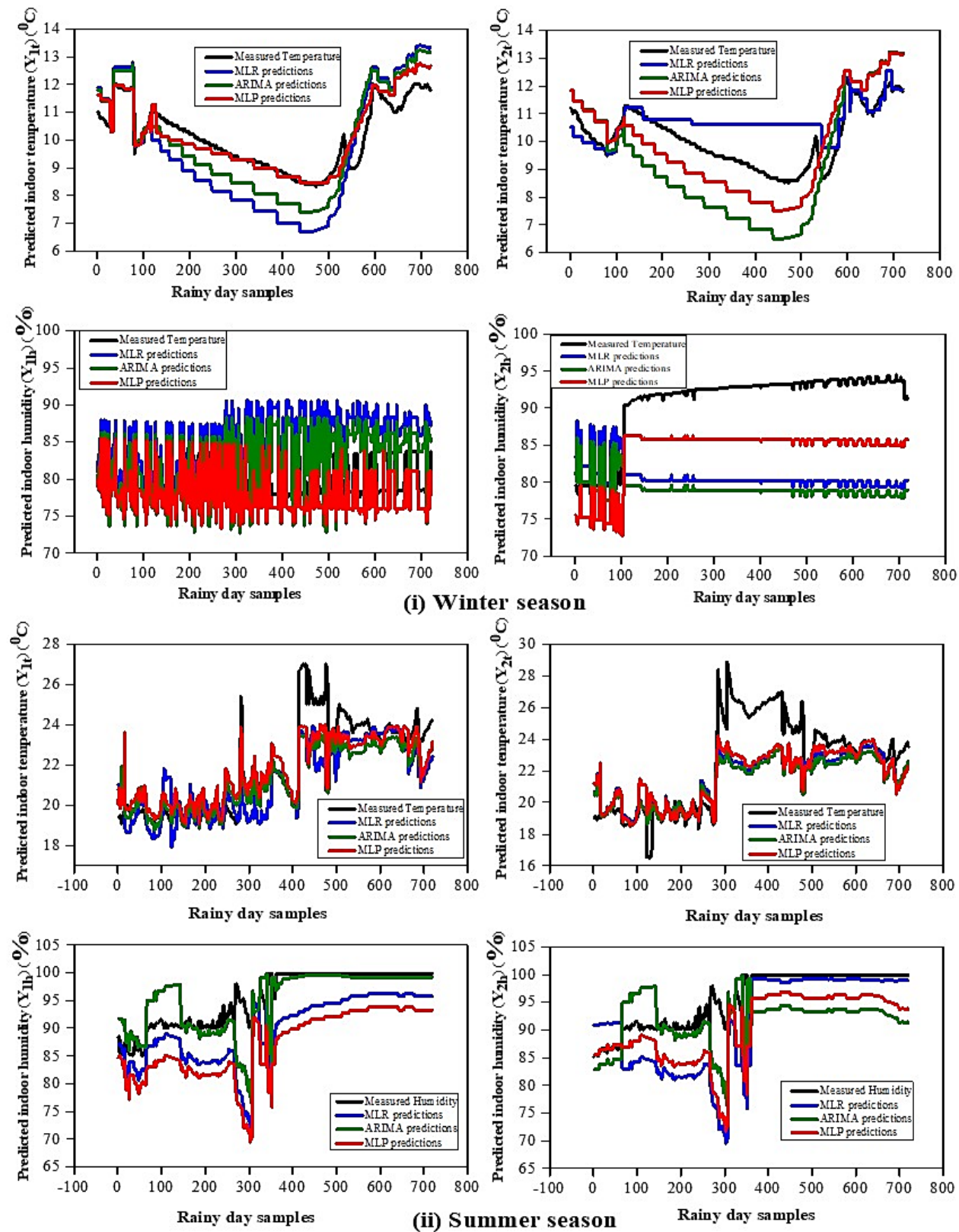

Figure 10. Comparison of measured data and predicted Indoor temperature (front) $\left(Y_{I_{t}}\right)$, Indoor temperature (back) $\left(Y_{2 t}\right)$, Indoor humidity (front) $\left(Y_{l h}\right)$, Indoor humidity (back) $\left(Y_{2 h}\right)$ by MLR, ARIMA, and MLP models for (i) Rainy days sample in winter season, (ii) Rainy days sample in summer season 


\section{Conclusion}

By mimicking the plant behavior according to the environmental growing conditions, the growers can produce better plants and save energy as well. With the use of the temperature controllers, humidification, and de-humidification control capabilities resulting in production of stronger and healthier plants. The current research presents a comparison between physical, time series model, and computational models to select the best method to predict the two indoor temperature parameters and two indoor humidity parameters for a greenhouse from external weather parameters. Also, predicting the indoor parameters with local weather station data and regional weather station data. According to the results, this study concluded with the following salient points,

[1] The results of performance evaluations showed that the regression model and the ARIMA model has incompetent results in particular for humidity predictions and should improve mathematic-experimental equations related to this parameter. For real-time implementation of this model, a fine-tuning and optimization required to strengthen the efficiency of the model.

[2] Either in the physical model or computational model, the addition of regional weather data as input for the prediction model that can increase the accuracy prediction value. Whereas the data addition produces desired output when using the other local weather parameters input data set nevertheless it is less performable when used as an individual input data set.

[3] The MLP (with BB training) model performed surpass then other models for the non-linear variables of greenhouse microclimate. According to the $\mathrm{R}^{2}$, MAE, RMSE, and MSE evaluations proofing that the superiority in prediction with the MLP model. For the real-time implementation, time consumption for learning and prediction as well needs to consider as one of the primary parameters, which could be possible by the MLP model.

[4] The present study developed a less complicated and fast learning MLP model, which is compatible with the online method, such as cloud-based modeling. In the future, the current model can be integrated into the computer through cloud technology in greenhouse controller devices to achieve better efficiency.

[5] By following this same methodology can develop models to predict soil temperature, soil moisture level, fuel consumption for heating and humidification, and $\mathrm{CO}_{2}$ emission in the greenhouses. It is possible to use the same try to collect some suitable data related to the above-mentioned parameters and investigate these features. Modeling soil temperature, soil moisture level, fuel consumption for heating and humidification, and $\mathrm{CO}_{2}$ emission would create more opportunities to utilize the advanced technologies for agriculture and modeling for better crop yield as well as a healthier environment for plants.

Acknowledgements. This research was supported by Korea Institute of Planning and Evaluation for Technology in Food, Agriculture and Forestry (IPET) through Agriculture, Food and Rural Affairs Research Center Support Program, funded by Ministry of Agriculture, Food and Rural Affairs (MAFRA) (Project No. 717001-7). 


\section{REFERENCES}

[1] Atia, D. M., El-madany, H. T. (2017): Analysis and design of greenhouse temperature control using adaptive neuro-fuzzy inference system. - Journal of Electrical Systems and Information Technology 4(1): 34-48.

[2] Behrang, M., Assareh, E., Ghanbarzadeh, A., Noghrehabadi, A. (2010): The potential of different artificial neural network (ANN) techniques in daily global solar radiation modeling based on meteorological data. - Solar Energy 84: 1468-1480.

[3] Braun, M. R., Altan, H., Beck, S. B. M. (2014): Using regression analysis to predict the future energy consumption of a supermarket in the UK. - Applied Energy 130: 305-313.

[4] Cheng, Q., Ni-Bin, C. (2011): System dynamics modeling for municipal water demand estimation in an urban region under uncertain economic impacts. - Journal of Environmental Management 92(6): 1628-1641.

[5] Choab, N., Allouhi, A., Maakoul, A. E., Kousksou,T., Saadeddine, S., Jamil, A. (2019): Review on greenhouse microclimate and application: Design parameters, thermal modeling and simulation, climate controlling technologies. - Solar Energy 191: 109-137.

[6] Davis, W. Y. (2003): Water Demand Forecast Methodology for California Water Planning Areas e Work Plan and Model Review. - In: Research Report. California Bay Delta Authority CA, USA.

[7] Dombayci, Ö., Gölcü, M. (2009): Daily means ambient temperature prediction using artificial neural network method: A case study of Turkey. - Renewable Energy 34: 11581161.

[8] Feinberg, E. A., Genethliou, D. (2005): Load Forecasting. - Applied Mathematics for Power Systems: 269-275.

[9] Hande, K., Sedat, B., Adil, A. (2016): A modeling study with an artificial neural network: Developing estimation models for the tomato plant leaf area. - Turkish Journal of Agriculture and Forestry 40: 203-212.

[10] Hasni, A., chikr Elmezouar, Z., Belkacem, D., Boulard, T. (2011): Applying Time Series Analysis Model to Temperature Data in Greenhouses. - Sensors and Transducers 126: 119124.

[11] He, F., Ma, C. (2010): Modeling greenhouse air humidity by means of artificial neural network and principal component analysis. - Computers and Electronics in Agriculture 71: 9-23.

[12] He, X., Guan, H., Zhang, X., Simmons, C. T. (2014): A wavelet-based multiple linear regression model for forecasting monthly rainfall. - International Journal of Climatology 34: 1898-1912.

[13] Jayalakshmi, T., Santhakumaran, A. (2011): Statistical normalization and back propagation for classification. - International Journal Computer Theory Engineering 3: 89-93.

[14] Khashei, M., Bijari, M. (2011): A novel hybridization of artificial neural networks and ARIMA models for time series forecasting. - Applied Soft Computing 11: 2664-2675.

[15] Kurt, B., Bruce, T. (2017): Future food-production systems: vertical farming and controlled-environment agriculture. - Sustainability Science Practice and Policy 13(1): 1326.

[16] Leonetti, A. (2018): By 2022, Smart Greenhouse Market to gain \$1.31 Bn. - Journal of Green Engineering: 110.

[17] Leopold, M., Pierre, M., Alexis, K. (2016): Application of artificial neural network for predicting hourly indoor air temperature and relative humidity in modern building in humid region. - Energy and Buildings 121: 32-42.

[18] Liu, X., Zhang, C., Liu, P., Yan, M., Wang, B., Zhang, J., Higgs, R. (2018): Application of Temperature Prediction Based on Neural Network in Intrusion Detection of IoT. - Security and Communication Networks: 1-10. 
[19] Lu, T., Viljanen, M. (2009): Prediction of indoor temperature and relative humidity using neural network models: model comparison. - Neural Computing and Applications 18(4): 345-357.

[20] Luan, X., Shi, P., Liu, F. (2011): Robust adaptive control for greenhouse climate using neural networks. - International Journal of Robust and Nonlinear Control 21: 815-826.

[21] Mehdi, R., Hossein, T., Yazdi, A. A., Sabahattin, I., Latif, K. (2013): Flood flow forecasting using ANN, ANFIS and regression models. - Neural Computing and Applications 25(1): 25-37.

[22] Murat, M., Malinowska, I., Gos, M., Krzyszczak, J. (2018): Forecasting daily meteorological time series using ARIMA and regression models. - International Agrophysics 32: 253-264.

[23] Neshat, N., Mahlooji, H., Kazemi, A. (2011): An enhanced neural network model for predictive control of granule quality characteristics. - Scientia Iranica 18(3): 722-730.

[24] Nury, A. H., Hasan, K., Alam, J. B. (2017): Comparative study of wavelet-ARIMA and wavelet-ANN models for temperature time series data in northeastern Bangladesh. Journal of King Saud University, Science 29(1): 47-61.

[25] Patel, D. P., Patel, M. M., Patel, D. R. (2014): Implementation of ARIMA model to predict Rain Attenuation for KU-band $12 \mathrm{Ghz}$ Frequency. - IOSR Journal of Electronics and Communication Engineering 9(1): 83-87.

[26] Santosh, D. T., Tiwari, K. N., Singh, V. K., Raja Gopala Reddy, A. (2017): Micro Climate Control in Greenhouse. - International Journal of Current Microbiology and Applied Sciences 6(3): 1730-1742.

[27] Shi, X., Lu, W., Zhao, Y., Qin, P. (2018): Prediction of Indoor Temperature and Relative Humidity Based on Cloud Database by Using an Improved BP Neural Network in Chongqing. - IEEE Access 6: 30559-30566.

[28] Singh, V. K., Tiwari, K. N. (2017): Prediction of greenhouse micro-climate using artificial neural network. - Applied Ecology and Environmental Research 15: 767-778.

[29] Taki, M., Ajabshirchi, Y., Ranjbar, F., Rohani, A., Matloobi, M. (2015): Heat transfer and MLP Neural Network models to predict inside environment variables and energy lost in a semi-solar greenhouse. - Energy and Buildings 110: 314-329.

[30] Taki, M., Yahya, A., Faramarz, R., Mansour, M. (2016): Application of neural networks and multiple regression models in greenhouse climate estimation. - Agricultural Engineering International: The CIGR e-journal 18: 29-43.

[31] Uchida Fraus, H., Pieters, J. G. (2004): Modelling greenhouse temperature using system identification by means of neural networks. - Neurocomputing 56: 423-428.

[32] Zhao, T., Xue, H. (2010): Regression Analysis and Indoor Air Temperature Model of Greenhouse in Northern Dry and Cold Regions. - IFIP Advances in Information and Communication Technology 345: 252-258. 